\title{
RAUMENU ANAEROBINIO DARBINGUMO IR CENTRINĖS NERVŲ SISTEMOS FUNKCINĖS BŪKLĖS RODIKLIŲ RYŠYS
}

\author{
Rita Sadzevičienė, Jūratė Kudirkaitė, Jonas Poderys \\ Lietuvos kūno kultūros akademija, Kaunas, Lietuva
}

Rita Sadzevičienė. Biomedicinos mokslų doktorantè. Lietuvos kūno kultūros akademijos Lengvosios atletikos katedros lektorè, Kineziologijos laboratorijos jaunesnioji mokslo darbuotoja. Mokslinių tyrimų kryptis — raumenų, širdies ir kraujagyslių sistemų funkcinės būklès rodiklių kaita mezociklo pratybose taikant aerobinius ir anaerobinius krūvius.

\begin{abstract}
SANTRAUKA
Šio tyrimo tikslas — palyginti Vingeito testu nustatomu anaerobinio darbingumo, CNS darbingumo ir funkcinės büklès rodikliu ryšl. Klasikiniais Tepingo ir Vingeito testais buvo registruojami funkciniai rodikliai, o vertinant ju panašuma - lyginami registruojamu rodikliu pokyčiai testavimo metu. Vingeito testu buvo nustatomas sportininku raumenu anaerobinio darbo galingumas ir anaerobinio darbo talpa. Specialia kompiuterine programa Tepingo testu buvo vertinamos CNS funkcinès büklès ir darbingumo rodikliu normalizuotos reikšmès: CNS paslankumas, asimetrija, nuovargis, bendras CNS darbingumas, anaerobinis darbingumas ir anaerobinio darbingumo talpa. Palyginę lengvaatlečiu, lavinančiu ištvermę ir greitumo jèga, rodiklius aptikome, kad greitumo jègos sportininkai CNS paslankumo rodikliais pranoksta ištvermès sportininkus, tačiau pastaruju CNS nuovargio rodikliai yra geresni. Vingeito testo metu registruojamas maksimalusis raumenu darbo galingumas buvo kur kas didesnis greitumo jègos grupeje, tačiau krūvio pabaigoje raumenu darbo galingumas jau buvo mažesnis nei ištvermès grupejje. Lygindami Vingeito testo raumenu darbo galingumo ir Tepingo testo rankos judesiu dažnio rodikliu pokyčius, aptikome stipria koreliacija tarp ju. Vadinasi, didelio meistriškumo sportininku anaerobinis darbingumas labai priklauso nuo CNS funkcinès büklès, todèl Ukrainos mokslininku sukurta Tepingo testo duomenu vertinimo metodika gali büti taikoma didelio meistriškumo sportininku anaerobinio darbingumo pokyčiams vertinti tomis situacijomis, kai didžiausiu pastangu reikalaujantys testai yra nepageidautini ar gali modifikuoti priešvaržybinio rengimosi eiga.
\end{abstract}

Raktažodžiai: centrinè nervu sistema, Tepingo testas, Vingeito testas, anaerobinis darbingumas.

\section{IVADAS}

$\mathrm{A}$ naerobinè alaktatinè ištvermè — tai gebèjimas kuo ilgiau atlikti maksimalaus intensyvumo darbą, kai ATP resintezé vyksta naudojant kreatinfosfato atsargas ir ADP (Maud, Foster, 1995; Зеленцов, Лобановский, 1998; Shephard, 2001). Ši ištvermè labiausiai priklauso nuo dirbančių raumenų bei CNS savybiu (Zijdewind et al., 2000). Anaerobinè alaktatinè ištvermè vertinama maksimalaus darbo kiekiu judejjimo užduočių metu - stengiantis atlikti kuo daugiau darbo per $20-30 \mathrm{~s}$ (Patton,
Duggan, 1987; Maud, Foster, 1995; Coleman, Hale, 1998).

Vingeito testas vienas iš plačiausiai taikomų metodų sportuojančiujų anaerobinio darbingumo rodikliams nustatyti (Patton, Duggan, 1987; Coleman, Hale, 1998; Зеленцов, Лобановский, 1998). Ukrainos kūno kultūros universiteto mokslininkai (Зеленцов, Лобановский, 1998) parengè CNS funkcinès būklès ir darbingumo rodiklių vertinimo metodika, pagal kurią klasikiniu Tepingo testu registruojami judesių dažnumo 
pokyčių rodikliai leidžia ịvertinti tiriamojo CNS paslankuma, nuovargi, bendra CNS darbinguma, anaerobini darbingumą ir anaerobinio darbo talpą. Tyrimo tikslas - išsiaiškinti Vingeito testu nustatomu anaerobinio darbingumo, CNS darbingumo ir funkcinès būklès rodiklių ryši.

\section{TYRIMO METODIKA}

Vingeito testo metu tiriamieji mynè veloergometro pedalus didžiausiomis pastangomis 30 sekundžių, iveikdami pasipriešinimą (7,5\% nuo kūno masès). Kas 5 sekundes buvo registruojamas raumenų išugdytas galingumas (W). Vingeito testo metu registravome absoliutuc ir santykini maksimaluji, vidutinị ir minimaluji galingumą bei galingumo mažèjimą per 30 sekundžių. Tai leido vertinti anaerobini darbingumą ir anaerobinio darbingumo talpa.

Judesiu dažnumo kitimas, atliekant klasikini 40 sekundžių trukmés Tepingo testą, buvo registruojamas specialia kompiuterine programa, sukurta Ukrainos kūno kultūros universiteto mokslininkų (Зеленцов, Лобановский, 1998).
Ji skirta CNS funkcinès būklès ir darbingumo rodikliams vertinti. Judesių dažnumas registruojamas kas 5 sekundes. Tai leido palyginti ištvermès (pirma tiriamuju grupè) ir greitumo jègos sportinin$\mathrm{ku}$ (antra tiriamujų grupè) darbingumo ir funkcinès būklès rodiklius: CNS paslankuma, nuovargi, bendrą CNS darbingumą, anaerobinị darbingumą ir anaerobinio darbingumo talpa.

Buvo tiriami 27 didelio meistriškumo lengvaatlečiai vyrai: 12 ištvermès rungčių sportininkų (amžius - 22,3 $\pm 4,35 \mathrm{~m}$; k kūno masè $-69,2 \pm 5,01 \mathrm{~kg}$; ūgis $-1,81 \pm 0,37 \mathrm{~m}$ ) ir 15 greitumo jègos rungčiu - sprinteriu grupe (amžius - 20,5 $\pm 1,79$ m.; kūno mase $76,0 \pm 5,07 \mathrm{~kg}$; ūgis $-1,84 \pm 0,42 \mathrm{~m})$.

\section{REZULTATAI}

Tepingo testo rezultatai. Tyrimo metu gauti sportininku CNS paslankumo, nuovargio, bendro CNS darbingumo, anaerobinio darbingumo ir anaerobinio darbingumo talpos duomenys pateikti 1 paveiksle. Kaip matyti, statistiškai reikšmingai

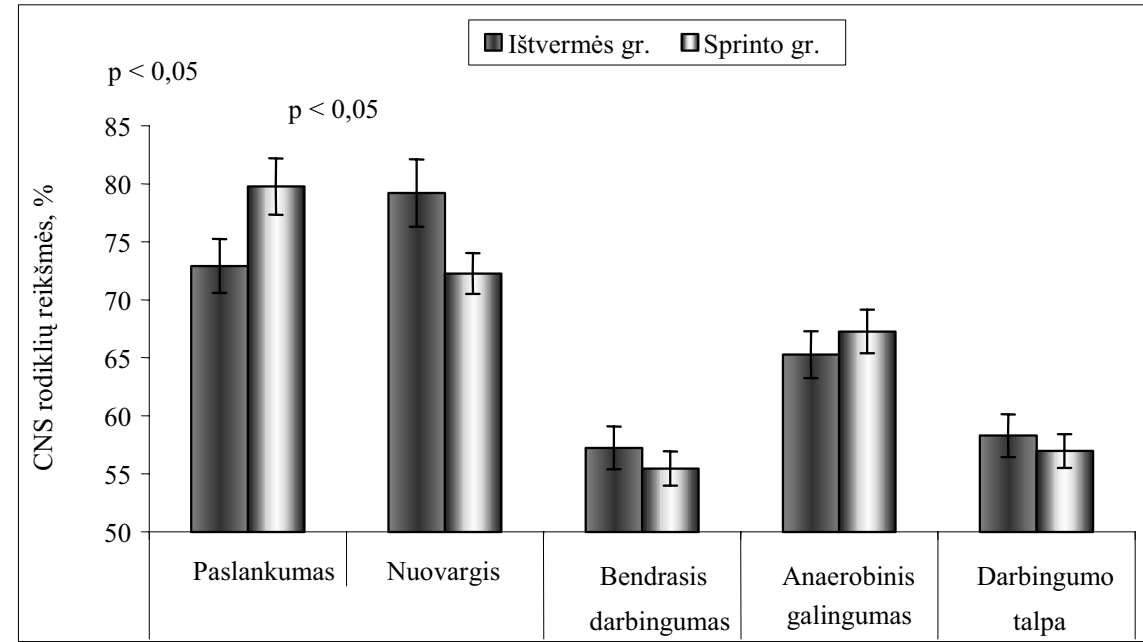

1 pav. Ištvermès ir sprinto grupių tiriamųjų Tepingo testo rodiklių palyginimas

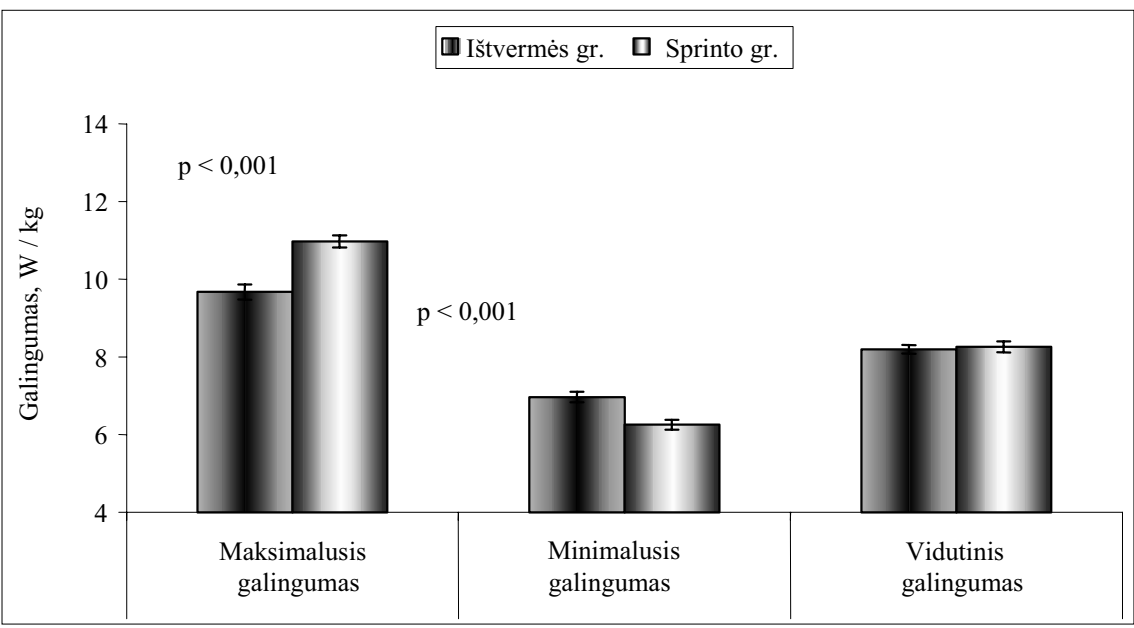

2 pav. Ištvermès ir sprinto grupių tiriamųjų Vingeito testo rodiklių palyginimas 
3 pav. Santykinio galingumo sumažèjimas atliekant Vingeito testą

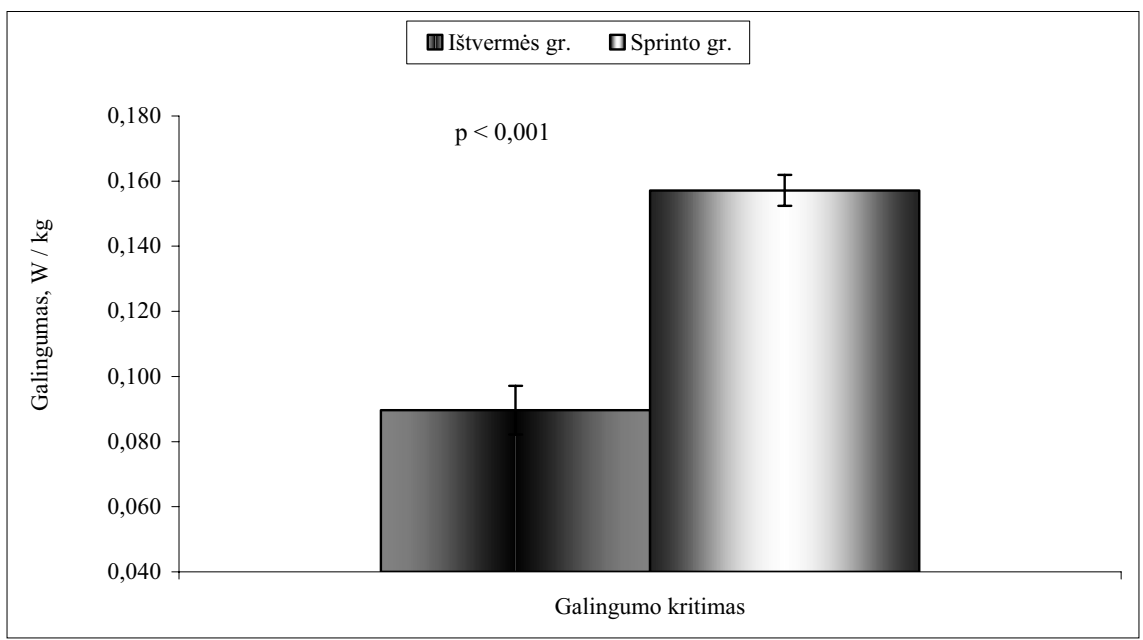

4 pav. Tiriamojo T. W. nuovargio kreivès pagal Vingeito ir Tepingo testu registruojamus duomenis (koreliacija $-\mathbf{0 , 9 8 2 )}$

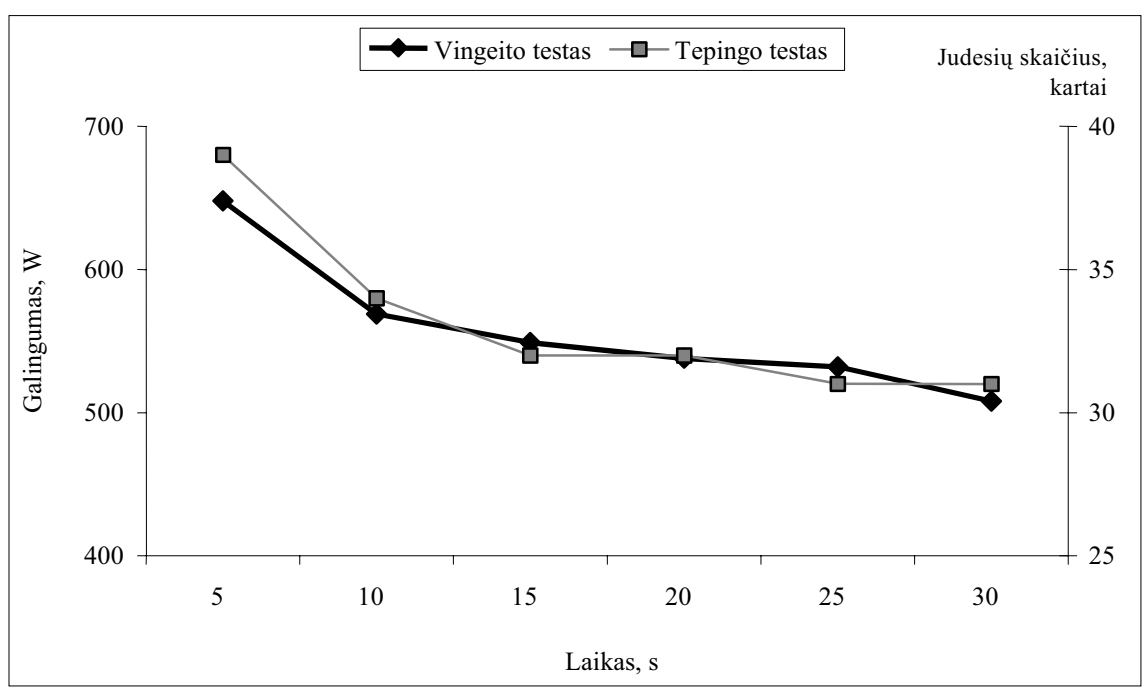

skyrèsi CNS paslankumo ir nuovargio rodikliai: CNS paslankumas geresnis sprinterių, o nuovargis $7 \%$ mažesnis ištvermès šakų sportininkų $(\mathrm{p}<0,05)$, lyginant rodiklius tarpusavyje.

Vingeito testo rezultatai. Atliekant 30 sekundžių trukmès veloergometrinị krūvị, buvo nustatytas tirtu sportininku maksimalusis, minimalusis ir vidutinis santykinis galingumas. Kaip matyti 2 paveiksle, statistiškai patikimai $(\mathrm{p}<0,05)$ skyrèsi maksimalios ir minimalios raumenų darbo galingumo reikšmès. Sprinterių grupès tiriamieji gebejo pasiekti kur kas didesni maksimaluji santykini galingumą, tačiau 30 sekundžių jo išlaikyti nesugebedavo, ir fizinio krūvio pabaigoje raumenų darbo galingumas nukrisdavo, o rodikliai būdavo prastesni už ištvermès šakų sportininkų. Viso (per 30 s) testo metu atlikto darbo rodikliai (t. y. užregistruotas vidutinis santykinis galingumas tarp ištvermès ir greitumo jègos grupių) statistiškai patikimai nesiskyrė $(\mathrm{p}<0,05)$.
Taigi vertinant raumenų darbo galingumo mažèjimą ( 3 pav.) matyti, kad anaerobinè alaktatinè ištvermé buvo geresne ištvermès rungčiu sportininku grupeje. Sprinterių raumenų maksimalusis galingumas (santykinis - W / kg kūno masès) beveik dvigubai greičiau mažèjo nei ištvermès grupejje.

Tepingo ir Vingeito testų duomenų palyginimas. Vingeito ir Tepingo testais užregistruotu tyrimo duomenų koreliacinė analizè parodè, kad abiejų testų metu užregistruoti nuovargio rodikliai reikšmingai tarpusavyje koreliuoja ir gali būti taikomi bei vertinami kaip analogai. 4 paveiksle pateikta vieno iš tiriamujų (ištvermès grupès sportininko) nuovargio kreivès pagal Vingeito ir Tepingo testu registruojamus duomenis. Koreliacija tarp šių rodiklių — 0,982 (stiprus ryšys). Iš 27 tiriamujų net $85 \%$ atveju abiejų testų duomenų pokyčiu koreliacija buvo nuo 0,80 iki 0,99 , ir aptiktas tik vienas atvejis, kai ši koreliacija buvo daug mažesnè $-0,502$. 


\section{REZULTATUQ APTARIMAS}

Didieji smegenų pusrutuliai, kaip aukščiausias organizmo santykių su aplinka palaikymo organas, yra pastovus organizmo vykdomu funkcijų kontrolierius (Shephard, 1987; Taylor et al., 1996). CNS siunčiamos komandos lemia raumenų pastangų dydị ir kitus tarpraumeninès koordinacijos ypatumus (Skurvydas, 1991; Taylor et al., 1996), todèl CNS darbingumo ir funkcinès būklès pokyčiai visada pastebimi iš raumenu veiklos rodikliu (Зеленцов, Лобановский, 1998; Shephard, 2001; Busco et al., 2002; McCarthy et al., 2002). Ši glaudi CNS ir raumenu funkcijos sąveika paaiškina CNS darbingumo, vertinamo Tepingo testu, ir raumenu anaerobinio darbo talpos, registruojamos Vingeito testu, rodikliu ryšit.

Sportuojančiujų darbingumui ir funkcinei būklei nustatyti yra naudojami fizinio krūvio mèginiai (Skurvydas, 1991; Зеленцов, Лобановский, 1998). Anaerobinio darbingumo pokyčiams vertinti labiausiai tinka judejjimo rezultatyvumą vertinantys testai. Jie geriau nei bet kuris atskirai paimtas biocheminis anaerobinio darbingumo rodiklis parodo i̇vykusiu pokyčiu laipsni (Maud, Foster, 1995). Maksimalaus intensyvumo fizinio krūvio testai nèra tinkami sportininko būklei vertinti, ypač tada, kai lieka nedaug laiko iki atsakingų varžybų. Tokiu atveju testavimas maksimalaus intensyvumo fiziniu krūviu yra papildomas, nepageidaujamas energijos eikvojimas ir organizmo varginimas. Anaerobiniam darbingumui įvertinti tinkamesnis yra Tepingo, o ne Vingeito testas. Apibendrinant šio tyrimo rezultatus galima teigti, kad Ukrainos mokslininku sukurta Tepingo testo duomenu vertinimo metodika gali būti taikoma sportininku anaerobinio darbingumo pokyčiams vertinti.

\section{IŠVADOS}

1. Didelio meistriškumo sportininkų anaerobinis darbingumas priklauso nuo CNS funkcinès būklès. Stipri koreliacija yra tarp nuovargio kreivių pokyčių pagal Vingeito ir Tepingo testų registruojamus duomenis.

2. Ukrainos mokslininkų sukurta Tepingo testo duomenu vertinimo metodika gali būti taikoma didelio meistriškumo sportininkų anaerobinio darbingumo pokyčiams vertinti tomis situacijomis, kai didžiausių pastangu reikalaujantys testai yra nepageidautini ar gali paveikti priešvaržybinio rengimosi eiga.

\section{LITERATŪRA}

Busco, T., Benoit, H., Bonnefoy, R., Feasson, L., Lacour, J. R. (2002). Effects of training frequency on the dynamics of performance response to a single training bout. Journal of Applied Physiology, 92 (2), 572-580.

Coleman, S. G., Hale, K. (1998). The effect of different calculation methods of flywheel parameters on the Vingeito Anaerobic Test. Canadian Journal of Applied Physiology, 23 (4), 409-417.

Maud, P. J., Foster, C. (1995). Physiological Assesment of Human Fitnes. USA: Human Kinetics.

McCarthy, J. P., Pozniak, M. A., Agre, J. C. (2002). Neuromuscular adaptations to concurrent strength and endurance training. Medicine and Science in Sports and Exercise, 34 (3), 511-519.

Patton, J. F., Duggan, A. (1987 ). An evaluation of tests of anaerobic power. Aviation, Space and Environmental Medicine, 58 (3), 237-242.

Shephard, R. J. (2001) Absolute versus relative intensity of physical activity in a dose-response context. Medicine and Science in Sports and Exercise, 33 (Suppl. 6), 400$418 ; 419-420$.
Shephard, R. J. (1987). Exercise Physiology. Toronto, Philadelphia: B. C. Decker inc.

Skurvydas, A. (1991). Organizmo adaptacijos prie fiziniu krūviu pagrindiniai dèsningumai. D. II. Vilnius. P. 417.

Taylor, J. L., Butler, J. E., Allen, G. M., Gandevia, S. C. (1996). Changes in motor cortical excitability during human muscle fatigue. Journal of Physiology, 15, 490, $519-528$.

Zijdewind, I., Zwarts, M. J., Kernell, D. (2000). Potentiating and fatiguing cortical reactions in a voluntary fatigue test of a human hand muscle. Experimental Brain Research, 130 (4), 529-532.

Зеленцов, А. М., Лобановский, В. В. (1998). Моделирование тренировки в футболе. Киев. 


\title{
RELATION BETWEEN INDICES OF FUNCTIONAL STATE OF CENTRAL NERVOUS SYSTEM AND ANAEROBIC PERFORMANCE
}

\author{
Rita Sadzevičienè, Jūratė Kudirkaitė, Jonas Poderys \\ Lithuanian Academy of Physical Education, Kaunas, Lithuania
}

\begin{abstract}
The purpose of this study was to find out the relation between the indices of anaerobic performance and the indices of the functional state of central nervous system. The Wingate Test, which is widely accepted in the assessment of anaerobic performance abilities, was used in this study. A special computer program was used for the assessment of changes in the frequency of movement during the Teping-Test. The results of the two groups of well-trained athletes in sprint or endurance events were compared. We have found the close relation between the changes in the frequency of movement during the Teping test and the changes of power during the Wingate Test. We conclude that there is a close relation between the anaerobic performance abilities of high-trained sportsmen and the functional state of central nervous system. The Teping Test can be useful for the evaluation of changes in anaerobic performance in cases of a short-term period before a competition.
\end{abstract}

Keywords: central nervous system, anaerobic performance, Teping-test, Wingate Test.

Gauta 2005 m. rugsèjo $12 \mathrm{~d}$.

Received on September 12, 2005 